\title{
EVIDENCE FOR 20, 22-EPOXYCHOLESTEROL AS AN INTERMEDIATE IN SIDE-CHAIN CLEAVAGE OF 22R-OH CHOLESTEROL BY ADRENAL CORTEX MITOCHONDRIA
}

\author{
R. J. KRAAIPOEL, H. J. DEGENHART, Vera van BEEK, Hannie de LEEUW-BOON, Gerdie ABELN, \\ H. K. A. VISSER and J. G. LEFERINK* \\ Department of Pediatrics, Erasmus University and Academic Hospital Rotterdam/Sophia Children's Hospital and Neonatal Unit \\ Gordelweg 160, Rotterdam, The Netherlands and * Laboratory for Toxicology, State University Utrecht, The Netherlands
}

Received 7 April 1975

\section{Introduction}

The cholesterol side-chain cleavage enzymesystem occurring in the adrenal cortex is able to convert cholesterol, $20 \alpha-\mathrm{OH}$ cholesterol $(20 \alpha)^{*}, 22 \mathrm{R}-\mathrm{OH}$ cholesterol (22R) and $20 \alpha, 22 \mathrm{R}$-di-OH cholesterol $(20 \alpha, 22 \mathrm{R})$ (inter alia) into pregnenolone and isocaproaldehyde. According to the 'classical scheme' the reactions are:

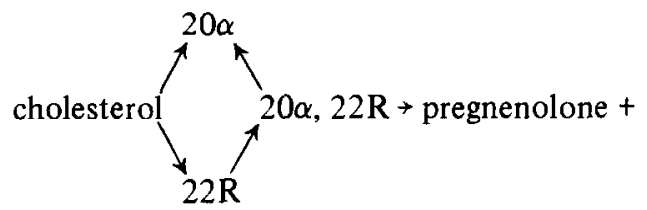

isocaproaldehyde

A direct conversion of cholesterol into $20 \alpha, 22 \mathrm{R}$ has also been proposed $[1,2]$. However evidence for two sequential mono-oxygenases or for a concerted attack of oxygen producing the dihydroxy cholesterol is still lacking. There are several other models of

Abbreviations: HEPES, $N$-2-hydroxyethylpiperazine- $N^{\prime}-2-$ ethanesulfonic acid; Cyanoketone, $2 \alpha$-cyano-4,4,17 $\alpha$-trimethyl$17 \beta$-hydroxy androst-5-en-3-one; Cholesterol, 5 -cholesten- $3 \beta$-ol; Epi-cholesterol, 5-cholesten-3 $\alpha$-ol; $20 \alpha-\mathrm{OH}$ cholesterol, 5-choles-

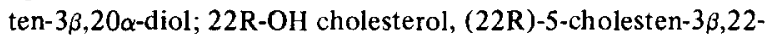

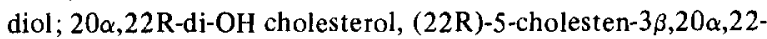
triol; 20 $\alpha, 22 \mathrm{~S}$-di-OH cholesterol, (22S)-5-cholesten- $3 \beta, 20 \alpha, 22$ triol; $\Delta^{20-22}$ cholesterol, 5,20(22)-cholestadien-3 $\beta-\mathrm{ol}$; 20,22-epoxy cholesterol, 20,22-epoxy-5-cholesten-3 $\beta$-ol; Pregnenolone, 5-pregnen-3 $\beta$-ol-20-one. cholesterol side-chain cleavage which also lack good experimental evidence [3-5].

We have studied the conversion of $22 \mathrm{R}$ into pregnenolone and isocaproaldehyde. In this paper the identity of the intermediate $20 \alpha, 22 \mathrm{R}$ will be established by a combination of gas chromatography and mass spectrometry. In addition we found that $20 \alpha, 22 \mathrm{R}$ is not the only intermediate. The results strongly suggest 20,22-epoxycholesterol to be an intermediate in the same reaction. The experiments support our previously presented hypothesis, according to which $22 \mathrm{R}$ is converted into pregnenolone and isocaproaldehyde via $\Delta^{20-22}$ cholesterol, 20,22-epoxycholesterol and 20 $\alpha, 22 \mathrm{R}-\mathrm{di}-\mathrm{OH}$ cholesterol [6] .

\section{Materials and methods}

Bovine adrenal cortex mitochondria were prepared according to standard procedures and stored directly in liquid nitrogen. Conversion of 22R-OH cholesterol into pregnenolone was estimated in a medium containing $154 \mathrm{mM} \mathrm{KCl}, 11.5 \mathrm{mM} \mathrm{NaCl}, 50 \mathrm{mM}$ nicotinamide, $20 \mathrm{mM}$ HEPES ( $\mathrm{pH} 7.3$ ), $5 \mathrm{mM} \mathrm{CaCl}_{2}, 4 \mathrm{mM}$ sodium azide, $1 \%$ bovine serum albumin $(\mathrm{w} / \mathrm{v})$ with a final vol of $25 \mathrm{ml}$. Incubations were carried out at $37^{\circ} \mathrm{C}$ in a thermostatically controlled vessel, the contents of which were magnetically stirred. The above 'freezedamaged' mitochondria ( $23 \mathrm{mg}$ protein) were used. Additions were made to achieve a final concentration of $30 \mu \mathrm{M}$ cyanoketone [7], $5 \mu \mathrm{M}$ antimycin $\mathrm{A}$, $0.1 \mathrm{mM}$ NADP, $3 \mathrm{mM}$ glucose 6-phosphate and 
$0.6 \mathrm{U} / \mathrm{ml}$ glucose 6-phosphate dehydrogenase.

After a $5 \mathrm{~min}$ preincubation at $37^{\circ} \mathrm{C}$ a sample was taken to correct for the pregnenolone formation from endogeneous chulesterol and 1300 nimol 22R-OH cholesterol (Ikapharm, Israel) were added to the medium.

Exp. 1-A: Every minute a $0.5 \mathrm{ml}$ sample was taken and extracted with ice-cold ethylacetate. The first sample was taken $10 \mathrm{sec}$ after addition of $22 \mathrm{R}-\mathrm{OH}$ cholesterol.

Exp. 1-B: Samples of $2 \mathrm{ml}$ were taken from the same incubation at intervals as indicated in fig. 1-B, added to $25 \mathrm{ml}$ erlenmeyers and immediately flushed with $100 \%$ carbonmonoxide $(500 \mathrm{ml} / \mathrm{min})$ for $120 \mathrm{sec}$. The contents were sealed off from air and incubated in a shaking incubator at $37^{\circ} \mathrm{C}$ for $20 \mathrm{~min}$. Reactions were also stopped by cold ethylacetate. Since it took CO $1 \mathrm{~min}$. to stop $22 \mathrm{R}$ conversion and pregnenolone formation, the indicated time at the abscissa of fig. 1-B is the time the sample was taken from the experiment (shown in fig. $1-\mathrm{A}$ ) plus 1 minute.

To all samples $20 \mu \mathrm{g} / \mathrm{ml}(50 \mu \mathrm{M})$ epi-cholesterol was added as an internal standard. Steroids were extracted with $3 \times 6 \mathrm{ml}$ distilled ethylacetate. The solvent was evaporated at room temperature with nitrogen. The extract was silylated and the steroids were quantified by gas chromatography as described [6]. All glassware had been cleaned with a potassium bichronate-sulfuric acid mixture and siliconized with Siliclad (Clay Adams).

Gaschromatographic analysis (fig.2) was performed at $250^{\circ} \mathrm{C}$ on a capillary column coated with Se-30,

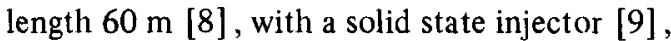
equipped with a flame ionizing detector (full scale in fig. $21 \times 10^{-11} \mathrm{~A}$ ) and with nitrogen as a carrier gas.

The mass spectra were obtained by a GC-MS combination as described by Leferink et al. [10]. The conditions were as follows: temperature of the column $230^{\circ} \mathrm{C}, \mathrm{GC} \cdot \mathrm{MS}$ interface $260^{\circ} \mathrm{C}$, source $230^{\circ} \mathrm{C}$, accelerating voltage $4 \mathrm{KeV}$, ionizing voltage $70 \mathrm{eV}$ and ionizing current $500 \mu \Lambda$.

Thin-layer chromatography was performed on silicagel (Merck $60 \mathrm{~F}_{254}$ ) with pentane : ether : glacial acetic acid $(60: 40: 2)$. 20 $\alpha, 22 \mathrm{~S}$-di-OH cholesterol was synthesized according to Chaudhuri et al. [11] using sodium borohydride reduction. Protein was estimated by the biuret method.

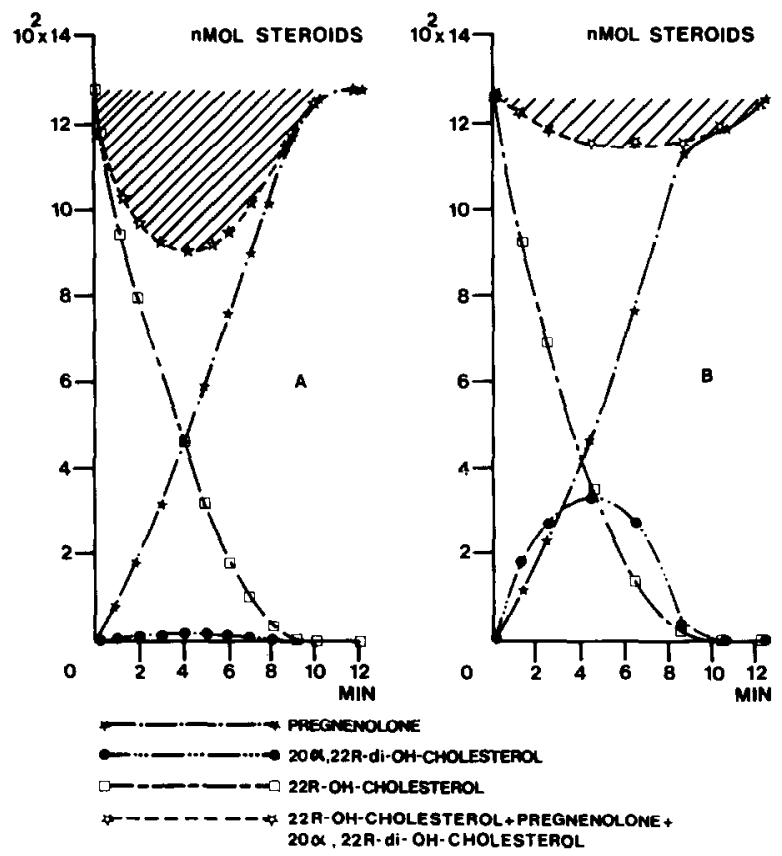

Fig.1. (A) Conversion of $22 \mathrm{R}-\mathrm{OH}$ cholesterol into pregnenolon by damaged bovine adrenal cortex mitochondria supported by a NADPH-generating system. $20 \alpha, 22 \mathrm{R}$ is formed as an intermediate. The shaded area represents the apparent 'massdefect'. The steroids were quantified after trimethylsilylation by GLC. (B) Samples taken during the reaction of the experiment shown in fig. 1(A) were immediately flushed with $100 \%$ carbon monoxide (methods). They were incubated airfree in a shaking incubator at $37^{\circ} \mathrm{C}$ for $20 \mathrm{~min}$. The shaded area decreases and $20 \alpha, 22 \mathrm{R}-\mathrm{OH}$ cholesterol increases. The indicated time at the abscissa has been corrected for the time it took $\mathrm{CO}$ to stop the reaction $\left(\mathrm{t}_{1-\mathrm{B}}=\mathrm{t}_{1-\mathrm{A}}+1 \mathrm{~min}\right.$.).

\section{Results}

In fig. 1 -A it can be seen that $22 \mathrm{R}(1300 \mathrm{nmol})$ disappears in $10 \mathrm{~min}$ and $1300 \mathrm{nmol}$ pregnenolone are formed. Assuming $20 \alpha, 22 \mathrm{R}$ to be the only intermediate in the conversion from $22 \mathrm{R}$ into the products pregnenolone and isocaproaldehyde, the sum (nmol) of 22R, 20 $\alpha, 22 \mathrm{R}$ and pregnenolone must be constant during the reaction. However the sum of the nmol substrate, intermediate and product is not constant. At $\mathrm{t}=4 \mathrm{~min}$ it is only $70 \%$ of the initial amount of substrate. Therefore $30 \%$ must be present in a form not detected by our gaschromatographic 


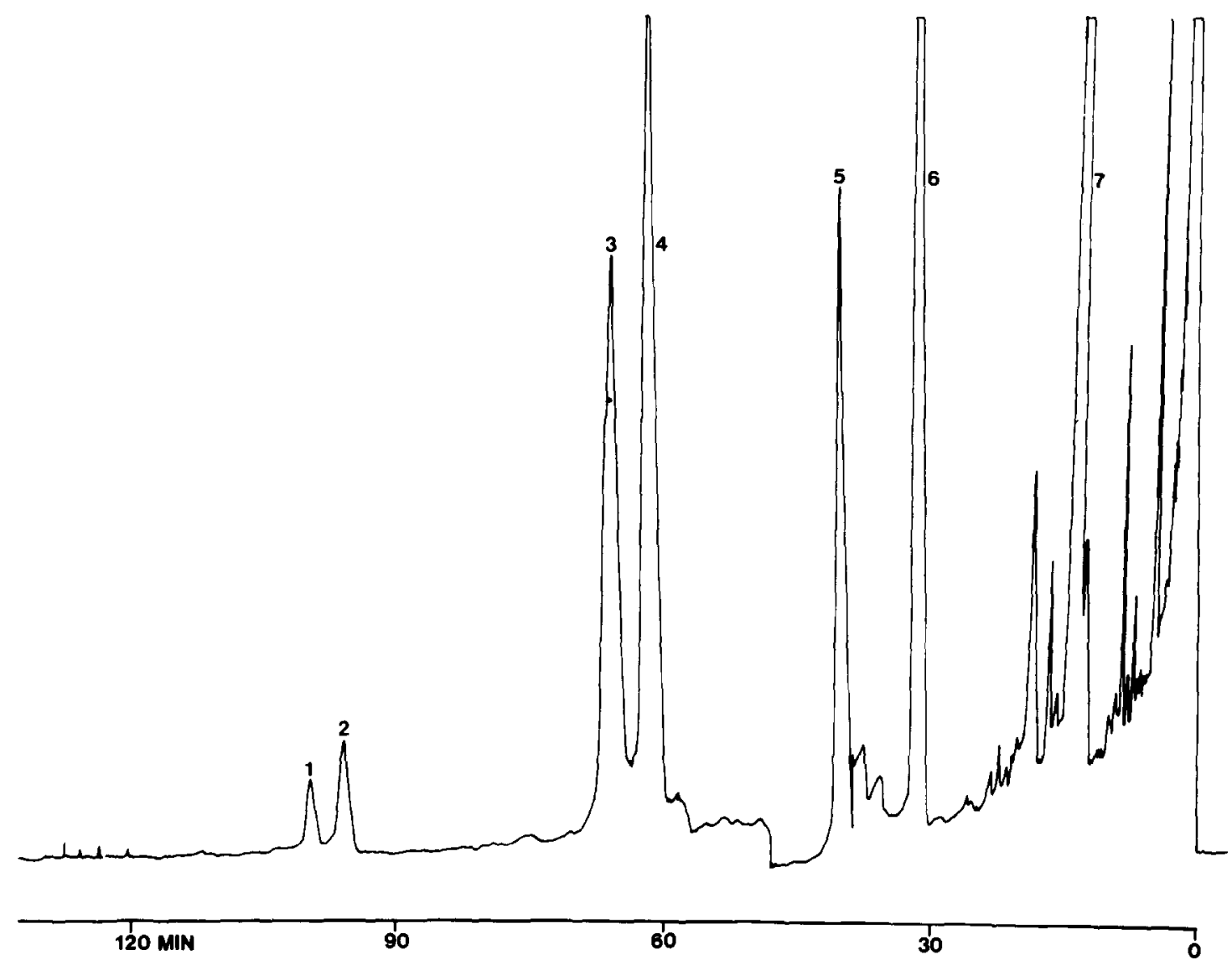

Fig.2. Gas-liquid chromatography of trimethylsilylated steroids on a capillary column (Metnoas): 1) 20 $\alpha, 22 \mathrm{R}$-di-OH cholesterol, 2) $20 \alpha, 22 \mathrm{~S}$-di- $\mathrm{OH}$ cholesterol, 3) $20 \alpha-\mathrm{OH}$ cholesterol, 4) $22 \mathrm{R}-\mathrm{OH}$ cholesterol, 5) cholesterol, 6) epi-cholesterol, 7 ) pregnenolone.

method. The time course of formation and disappearance of this or these compounds is represented by the shaded area of fig.1-A. Analysis of the samples (taken from the experiment shown in fig.1-A), incubated for 20 min under carbon monoxide (see Methods) and thus with complete inhibition of cytochrome $P-450$, shows a marked increase in $20 \alpha, 22 \mathrm{R}$ and a proportional decrease in the shaded area (fig. 1-B). Apparently the compound(s) not measured by our method are in the presence of $\geqslant 99 \%$ CO converted into $20 \alpha, 22 \mathrm{R}$.

Fig. 2 shows a gas chromatogram obtained with a capillary column. The sample was taken at $t=4 \mathrm{~min}$ (fig.1-B) and injected together with a mixture of pregnenolone, epi-cholesterol, cholesterol, 22R-OH cholesterol, $20 \alpha-\mathrm{OH}$ cholesterol and $20 \alpha, 22 \mathrm{~S}-\mathrm{di}-\mathrm{OH}$ cholesterol. The biological intermediate $20 \alpha, 22 \mathrm{R}$ is clearly separated from the synthetically prepared $20 \alpha$, 22S-di-OH cholesterol, while the mass spectra of both compounds are almost identical (fig.3).

Thin-layer chromatography (fig.4) of samples taken from an incubation analogous to the one shown in fig. $1-\mathrm{A}$ is in accord with the gaschromatographic analysis and supplements it. $22 \mathrm{R}$ decreases and pregnenolone is formed. Cholesterol from mitochondria origin is detected in all samples. However a compound with $R_{\mathrm{f}}=0.37$ is detectable during the reaction. It is neither present at the start of the reaction $(\mathrm{t}=0 \mathrm{~min})$ nor after the reaction has come to an end $(t=11 \mathrm{~min})$.

Isolation of the unknown substance from thin-layer plates followed by silylation and gas chromatography showed the presence of a neglible amount of $20 \alpha$, $22 R$ as might be expected from the results, represented 

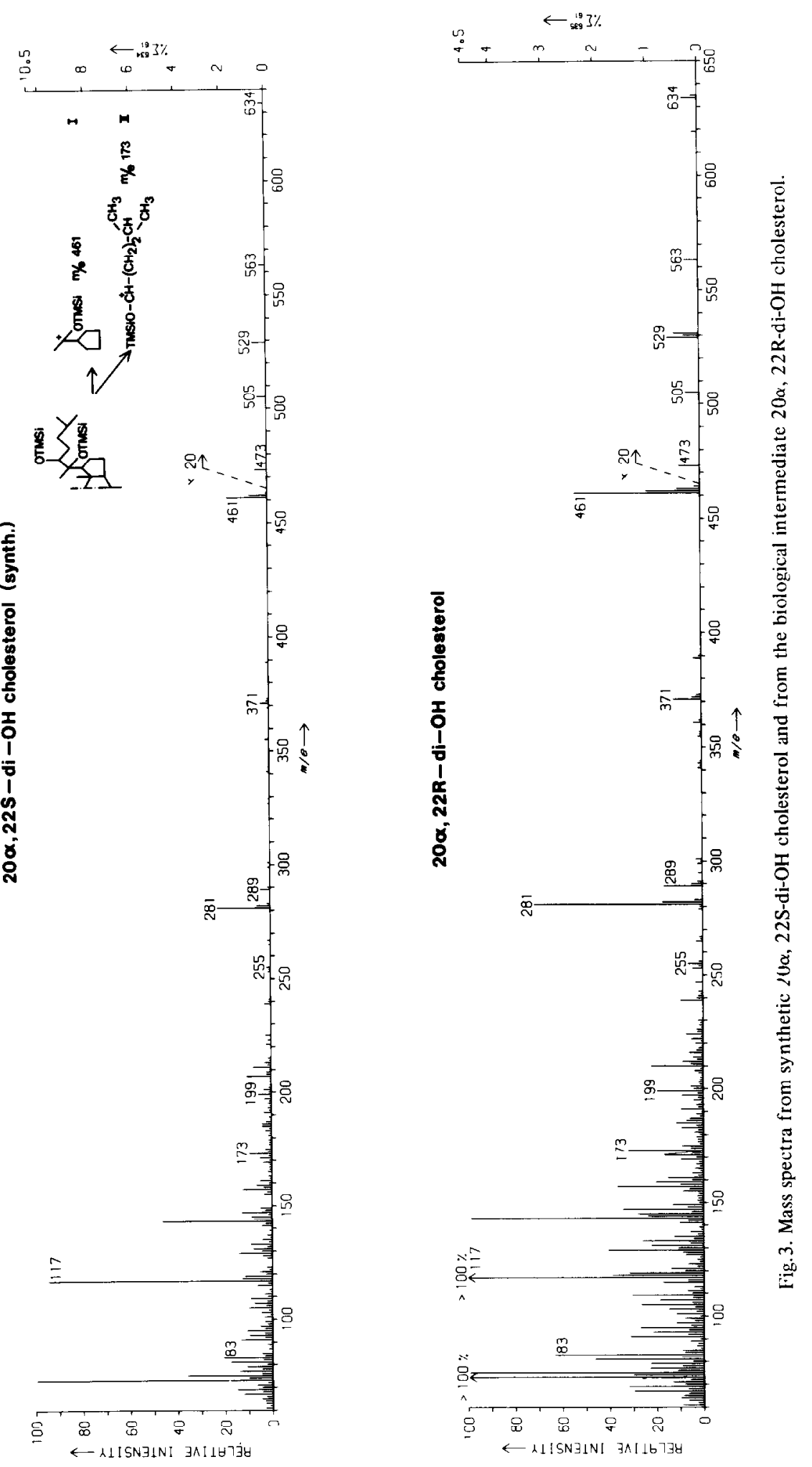


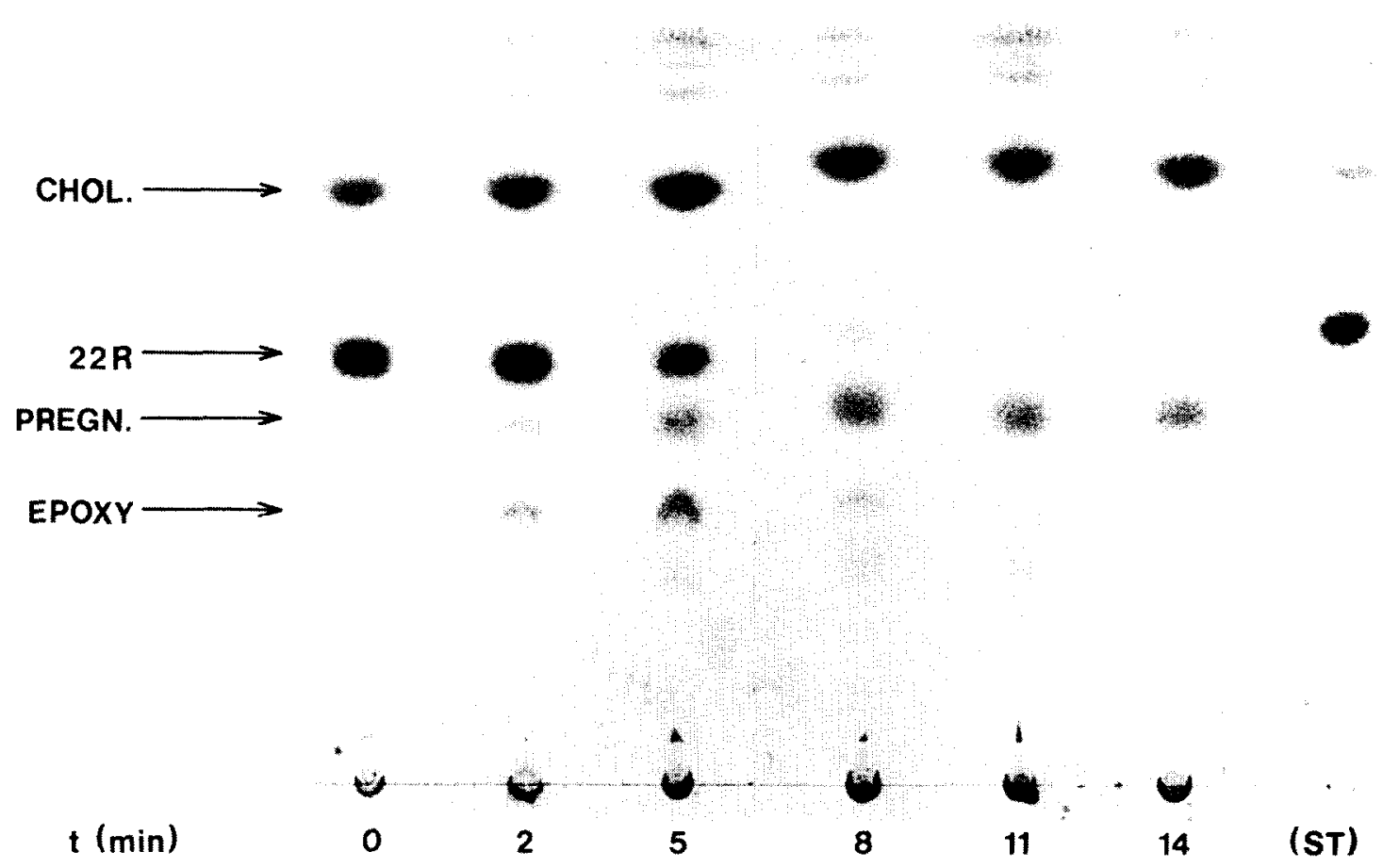

Fig.4. Thin-layer chromatography of samples taken from an experiment analogous to the one described in fig.1. (A). Cholesterol of mitochondrial origin is present in all samples. At $\mathrm{t}=2,5$ and $8 \mathrm{~min}$ a spot with $R_{\mathrm{f}}=0,37$ is visible, preliminarily identified as 20,22 epoxycholesterol.

by fig.1-A. Chemical hydrolysis with perchloric acid [12] converted the unknown compound into 20,22 di-OH cholesterol.

\subsection{Discussion of the mass spectra}

The upper part of fig. 3 is the mass-spectrum of persilylated $20 \alpha, 22 \mathrm{~S}$-di-OH cholesterol. The molecular weight of the compound is 634 . Characterisation of some important fragments demonstrates the location of the hydroxylgroups in the side-chain.

The fragment at $\mathrm{m} / \mathrm{e} 563$ indicates a simple fission of the $22-23$ bond, and loss of an additional $\left(\mathrm{CH}_{3}\right)_{3}$ $\mathrm{Si}-\mathrm{OH}$ group produces a fragment at $\mathrm{m} / \mathrm{e} 473$. The peaks at $\mathrm{m} / \mathrm{e} 461$ (fragment $\mathrm{I}$ ) and $\mathrm{m} / \mathrm{e} 173$ (fragment II) are due to fission of the $20-22$ bond with the charge located on either the large or the small fragment (see insert of fig.3). The fragments at $\mathrm{m} / \mathrm{e} 371$ and $\mathrm{m} / \mathrm{e} 281$ are formed from fragment I by losing one or two $\left(\mathrm{CH}_{3}\right)_{3} \mathrm{Si}-\mathrm{OH}$ groups respectively. Analogous to this fragment II will give a peak at $\mathrm{m} / \mathrm{e} 83$. The peak at $\mathrm{m} / \mathrm{e} 117$ could be explained by production of another small fragment by cleavage of the C17-20 bond in fragment I after hydrogen transfer from the steroid skeleton with the charge remaining at the C-20 site. Cleavage of the total side-chain is responsible for the fragment at $\mathrm{m} / \mathrm{e} 289$; it will also lose one $\left(\mathrm{CH}_{3}\right)_{3}$ Si-OH group, yielding a peak at $\mathrm{m} / \mathrm{e} 199$.

The lower mass spectrum in fig. 3 is that of the biological intermediatc and compares extremely well with the upper spectrum. From these spectra and the gaschromatogram the conclusion is justified that the intermediate is $20 \alpha, 22 \mathrm{R}$-di-OH cholesterol. The mass spectrum is similar to the spectrum from the same compound isolated from meconium [13] with slight changes for the underivatised $20 \alpha-\mathrm{OH}$ group. 


\section{Discussion}

According to the experiments described an intermediate between $22 R$ and $20 \alpha, 22 R$ must be present when $22 \mathrm{R}$ is converted into pregnenolone and isocaproaldehyde. A peroxide as a physiological intermediate is highly improbable. All tests on peroxides as described in Feigl [14] and Stahl [15] indicated the presence of only traces of peroxides. In addition, the concentration of these trace amounts did not vary significantly in time.

The following evidence strongly suggests that an epoxide is an intermediate.

1. Both chemical $\left(\mathrm{HClO}_{4}\right)$ and enzymatic hydrolysis (fig.1-A, 1-B) yield 20,22-di-OH cholesterol.

2. ${ }^{18} \mathrm{O}$ from $\mathrm{H}_{2}{ }^{18} \mathrm{O}$ is incorporated in $20 \alpha, 22 \mathrm{R}$ with $22 \mathrm{R}$ as starting product [6]. Assuming 20,22-epoxycholesterol is an intermediate in the side-chain cleavage reaction this could easily be explained. It is incompatible with the consecutive or concerted action of two hydroxylases (mono-oxygenases).

3. Epoxides can react with silylation agents in the following way [16]:<smiles>[Y5]OC(C)(C)C([Y])(C)C([X])(C)C</smiles>

( $\mathrm{X}=\mathrm{Cl}, N$-methylacetamide, imidazole)

The products of such silylation reactions are known to have low volatility [17]. Thus on considering the reaction between 20,22-epoxycholesterol and trimethylsilylimidazole one would expect a similar derivative, unsuitable for gas chromatography owing to its low volatility.

It can be seen that under the conditions of exp. 1-A the epoxy-hydrase is rate limiting. In the presence of $\geqslant 99 \%$ CO (fig. 1-B) neither is an epoxide formed nor is $20 \alpha, 22 \mathrm{R}$ converted; however the epoxy-hydrase is able to catalyze the conversion of 20,22-epoxycholesterol into $20 \alpha, 22 \mathrm{R}$. The following explanation can now be given. The conversion of $20 \alpha, 22 \mathrm{R}$ into pregnenolone is known to require $\mathrm{NADPH}$ and $\mathrm{O}_{2}$; cytochrome $P-450$ is involved and the reaction is inhibited by $\mathrm{CO}[18,19]$. Epoxidation of double bonds in the liver is also known to be cytochrome $P$-450- or $P$-448-dependent; NADPH and $\mathrm{O}_{2}$ are
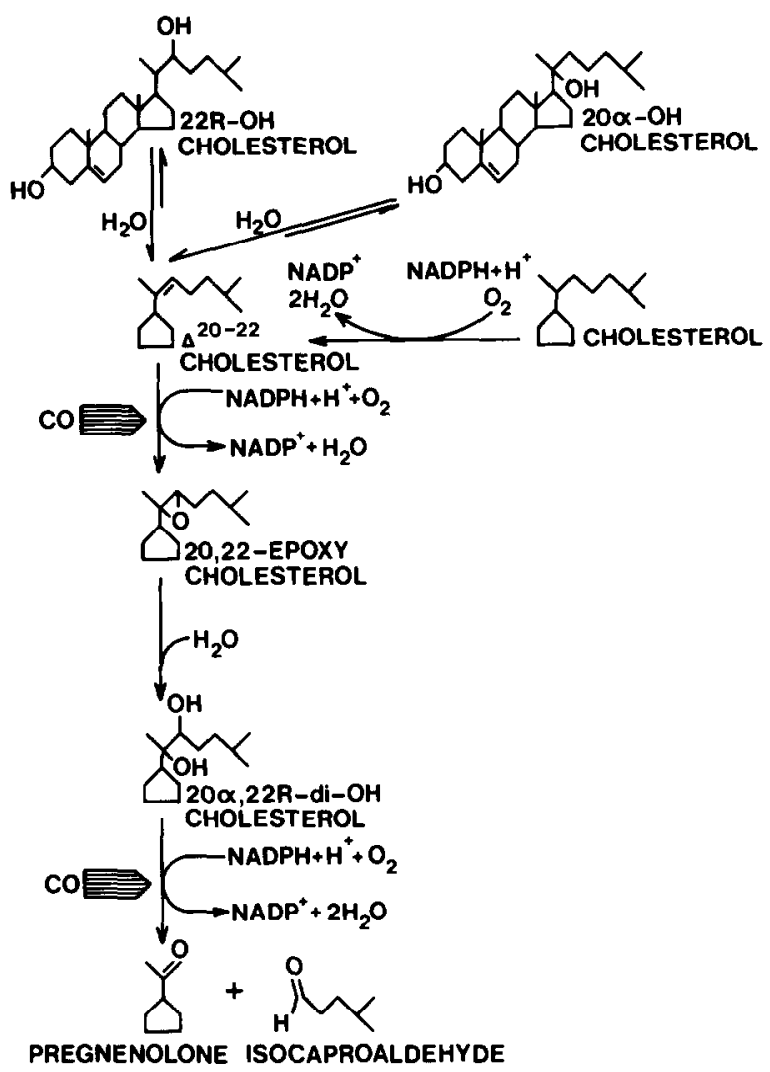

required [20-22]. By analogy one could therefore expect in exp. 1-B both the formation of the cholesterol epoxide and the conversion of $20 \alpha, 22 \mathrm{R}$ to be inhibited by $\mathrm{CO}$. The data obtained support our recently proposed hypothesis [6] concerning cholesterol sidechain cleavage (fig.5).

One might expect $20 \alpha-\mathrm{OH}$ cholesterol to behave in a manner similar to $22 \mathrm{R}$, since conversion of the sterol in the presence of $\mathrm{H}_{2}{ }^{18} \mathrm{O}$ gave rise to ${ }^{18} \mathrm{O}$ containing pregnenolone [6]. However the phenomena shown in fig. 1-A have not been found with $20 \alpha$ as a substrate (unpublished experiments, R. J. Kraaipoel), probably because the conversion $20 \alpha \rightarrow \Delta^{20-22}$ is slower than $22 R \rightarrow \Delta^{20-22}$. The epoxy-hydrase reaction therefore is no longer the rate limiting step. It is also possible to explain the different behaviour of $20 \alpha$ and $22 \mathrm{R}$ with respect to the apparent 'mass-defect' by postulating the formation of two different epoxides (20 $\alpha, 22 \alpha$-epoxycholesterol and $20 \beta, 22 \beta$-epoxycholesterol). This would agree with our earlier suggestior 
[6] that $\Delta^{20-22}$ cholesterol originating from $20 \alpha$ is attached to the enzyme surface in a stereochemically different way than $\triangle^{20-22}$ cholesterol originating from 22R.

It is of some interest that several epoxy-hydrases have been described $[22,23]$. Recently it was reported that $5 \alpha, 6 \alpha$-epoxy-cholesterol, a known carcinogen, is formed continuously in the skin under the influence of light. It is transformed by a $5 \alpha, 6 \alpha$-epoxy-hydrase into cholestane-3 $\beta, 5 \alpha, 6 \beta$-triol [24].

Burstein et al. [25], using acetone extracted bovine adrenal cortex mitochondria, tentatively identified $20 \alpha, 22 \mathrm{R}$ as an intermediate by recrystallisation techniques. This has now been confirmed by our experiments. The time course of their reaction $[1,2]$, using this material, was similar to the one shown in fig. 1-B but no 'mass-defect' was found. An explanation for the discrepancy was found when we used mitochondrial preparations stored under poor conditions (the storage container was not refilled in time with liquid nitrogen). A conversion of $22 \mathrm{R}$ into pregnenolone according to fig. 1-B was repeatedly demonstrated. We found earlier that the enzymatic conversion of $20 \alpha$, $22 \mathrm{R}$ into pregnenolone and isocaproaldehyde is very susceptible to inhibition. Contact with air when mitochondria are in a freeze-dried condition also selectively damages this last step [6]. The epoxyhydrase is no longer rate limiting and thus no epoxide but $20 x, 22 \mathrm{R}$ accumulates. This may be the reason why some investigators found $20 \alpha, 22 \mathrm{R}$ as an intermediate and others did not.

It is tempting to speculate about the four enzymatic activities, needed to convert cholesterol into pregnenolone. According to our scheme these are an oxidative desaturase [26], an epoxidase, an epoxy-hydrase and a lyase (desmolase). We suggest that the epoxidase and lyase activities belong to the group of cytochromes $P$-450. It is interesting to compare this with the cy tochrome $P-450$ preparation isolated by Shikita and Hall [27,28], containing 8 heme groups per molecule $P$-450. It appears that this adrenocortical $P$-450 (mol. wt 850000 ) is isolated in a form consisting of 16 subunits and can exist in forms of 8 (mol. wt $470000)$ and 4 (mol. wt 200 000) subunits. Drastic treatments result in the formation of single units. The fragment of 4 subunits (after addition of the specific flavoprotein and non-heme iron protein) was still able to convert cholesterol into pregnenolone [19]. This is clearly an area that requires further research and elucidation.

\section{Acknowledgements}

Mrs Mary Amesz-Heinrich, Mr A. A. M. Kempers and Dr D. A. Price are gratefully acknowledged for their help with the preparation of the manuscript. Cyanoketone was a gift from Sterling-Winthrop. This work was supported by a grant from the Netherlands Foundation for Fundamental Medical Research.

\section{References}

[1] Burstein, S., Kimball, H. L. and Gut, M. (1970) Steroids $15,809-857$.

[2] Burstein, S. and Gut, M. (1971) Recent Progress in Hormone Research 27, 303-349.

[3] Van Lier, J. E. and Smith, L. L. (1970) Biochim. Biophys. Acta 210,153-163.

[4] Van Lier, J. E. and Smith, L. L. (1970) Biochem. Biophys. Res. Commun. 40, 510-516.

[5] Luttrell, B., Ilochberg, R. B., Dixon, W. R., McDonals, P. D and Lieberman, S. (1972) J. Biol. Chem. 247, 1462-1472.

[6] Kraaipoel, R. J., Degenhart, H. J., Leferink, J. G., Van Beek, V., de Leeuw-Boon, H. and Visser, H. K. A. (1975) FEBS Lett. 50, $204-209$.

[7] Goldman, A. S. (1967) J. Clin. Endocr. 27, 325-332.

[8] Rutten, G. A. F. M. and Luyten, J. A. (1972) J. Chromatogr. 74, 177-181.

[9] Van den Berg, P. M. J. and Cox, Th. P. H. (1972) Chromatographia 5, 301-305.

[10] Leferink, J. G. and Leclercq, P. A. (1974) J. Chromatogr. 91, 385-391

[11] Chaudhuri, N. K., Nickolson, R., Kimball, H. L. and Gut, M. (1970) Steroids 15, 525-539.

[12] Fiescr, L. F. and Fieser, M. (1967) Reagents for Organic Synthesis, p. 796, John Wiley and Sons, Inc. New York, London, Sydney.

[13] Eneroth, P. and Gustafsson, J. A. (1969) FEBS Lett. 5, $99-103$.

[14] Feigl, F. (1971) Spot Tests in Organic Analysis, 7 th Engl. Edn. Elsevier Publ. Comp., Amsterdam, London, New York.

[15] Stahl, E. (1967) Dünnschicht Chromatographie, zweite Auflage Springer Verlag, Berlin, Heidelberg, New York.

[16] Birkofer, L., Dickopp, H. (1969) Chem. Ber. 102, 14-22.

[17] Stoming, T., Knapp, D. and Bresnick, E. (1973) Life Sci. $12,425-429$.

[18] Shimizu, K. (1968) Arch. Biochem. Biophys. 125, 1016-1017. 
[19] Shikita, M. and Hall, P. F. (1974) Proc. Natl. Acad. Sci. U.S.A. 71, 1441-1445

[20] Brodie, B. B., Reid, W. D., Cho, A. K., Sipes, G., Krishna, G. and Gillette, J. R. (1971) Proc. Natl. Acad. Sci. U.S.A. $68, \mathrm{~J} 60-164$.

[21] Jerina, D. M., Daly, J. M., Witkop, B., Zaltzman-Nirenberg, P. and Udenfriend, S. (1970) Biochemistry 9, 147-155.

[22] Dansette, P. M., Yagi, H., Daly, J. W., Levin, W., Lu, A. Y. H., Kuntzman, R. and Conney, A. H. (1974) Arch. Biochem. Biophys. 164, 511-517.
[23] Breuer, H. and Knuppen, R. (1961) Biochim. Biophys. Acta 49, 620-621.

[24] Chan, J. T. and Black, H. S. (1974) Science 186, 1216-1217.

[25] Burstein, S., Zamoscianyk, H., Kimball, H. L., Chaudhuri, N. K. and Gut, M. (1970) Steroids 15 , 13-60.

[26] Fulco, A. J. (1974) Ann. Rev. Biochem. 43, 215--241.

[27] Shikjta, M. and Hall, P. F. (1973) J. Biol. Chem. 248, 5598-5604.

[28] Shikita, M. and Hall, P. F. (1973) J. Biol. Chem. 248, 5605-5609. 